\title{
La crisis del concepto prudencia a causa del tránsito de las normas nacionales austriacas de información financiera a las normas internacionales ${ }^{1}$
}

\author{
Michael Matthias Reeh \\ Universidad de Economía y \\ Negocios de Viena \\ a9709930@unet.univie.ac.at
}

\section{Nelson Andrés}

Molina Roa

Universidad de La Salle nelsonmolina@unisalle.edu.co

\section{Resumen}

Al ser un país miembro de la Unión Europea (UE), la nación austriaca ha venido incorporando paulatinamente las International Financial Reporting Standards (IFRS), Normas Internacionales de Información Financiera (NIIF) en español, a sus procesos contables y de revelación de información financiera en remplazo de las normas nacionales locales conocidas como Unternehmensgesetzbuch (UGB). Durante este proceso de convergencia, el principio prudencia ha entrado en crisis dentro del marco conceptual de las IFRS a cambio del principio valor justo o razonable. Es por ello que este trabajo presenta los principios básicos del sistema austriaco nacional, UGB, en comparación con los de las IFRS con el fin de analizar, por un lado, las razones por las cuales el concepto prudencia entro en crisis y, por otro, si el principio valor justo o razonable es el indicado para remplazar al primero.

Palabras clave: Austria, Normas Internacionales de Información Financiera, principio de prudencia, principio de valor justo. 


\title{
Prudence concept crisis because of transition of austrian national financial information norms to international financial reporting standards
}

\begin{abstract}
As a member of the European Union (EU), Austrian nation has gradually incorporated International Financial Reporting Standards (IFRS), Normas Internacionales de Información Financiera (NIIF) in spanish, to its accounting and Disclosure of Financial Information processes in replacement of Local National Standards called Unternehmensgesetzbuch (UGB). During this process of convergence, prudence principle has been in crisis within IFRS conceptual frame because it has been changed by fair value principle. That is way this paper presents the basic principles of national Austrian, UGB, compared with those of the IFRS to analyze, first, the reasons why prudence concept went into crisis and, secondly, if fair value principle is right to replace it.
\end{abstract}

Keywords: Austria, International Financial Reporting Standards, principle of prudence, principle of fair value.

\section{Introducción}

El objetivo básico de la contabilidad es informar sobre el estado financiero de una empresa (Bailey y Miller 1998). En esencia, el contador ofrece una valoración monetaria de las actividades económicas de las organizaciones y una descripción textual que explica las decisiones y acciones que, a lo largo de un determinado periodo, ha venido tomando la gerencia (Coenenberg, Haller y Marten, 1999; Fortin, Hirata y Cutler, 2010); sin embargo, a la luz de los procedimientos de revelación de información, de esta definición surgen algunas cuestiones: ¿cómo se consideran los riesgos y los potenciales?, ¿cómo se puede determinar el valor de bienes, deudas, patrimonio y actividades?, ¿se consideran dentro de la revelación de los estados financieros todos los factores que influyen en el valor de un bien?, ¿deben considerarse los factores de cambio a la hora de valorizar un bien dentro de un periodo?, ¿el precio que la empresa paga por un bien, es su verdadero valor?

\footnotetext{
${ }^{1}$ El presente artículo es producto de las actividades de intercambio académico y de investigación internacional que el programa de Contaduría Pública de la Facultad de Ciencias Administrativas y Contables de la Universidad de La Salle, Bogotá, Colombia, realiza como parte de sus desarrollos de investigación disciplinares.
} 
Sobre este tema, en Austria actualmente existen dos teorías distintas reflejadas en las Unternehmensgesetzbuch (UGB, Normas Austriacas de Información Empresarial) (RIS, 2010) y en las Normas Internacionales de Información Financiera, en adelante NIIF (IFRS, 2010). La diferencia entre una y otra depende del grupo de interés al que va dirigida la información contable; mientras la UGB se enfoca en proteger a los acreedores desde el principio de la prudencia, las NIIF se enfocan en los inversionistas desde el principio del valor justo o razonable (Ehrlich, 2011; Hayn, Waldersee y Graf 2010).

Una de las razones de ser de las normas internacionales de contabilidad es la consistencia con la perspectiva del inversor, condición que el documento predecesor Modelo comprensivo para el reporte de información financiera para inversores, desarrollado por el Certificate Financial Analyst Institute en 2007 (citado en AICPA, 2009), proclamó como necesario para que los mercados globales llegaran a ser libres, eficientes y con oportunidad para todos los tipos de inversores de tener un rendimiento justo.

Ser consistente con los intereses de los inversores implica "defender que los estados financieros se dirijan a satisfacer las necesidades e intereses de los proveedores de capital empresarial como usuarios de la información sean estos propietarios o prestamistas que financian la inversión y las operaciones de las corporaciones con responsabilidad pública de rendir cuentas" (Mejía, 2011).

En esencia, los principios básicos de los que parte el CFAI (en español, Instituto de Análisis Financieros Certificados) son los siguientes:

- Los estados financieros principales deben contener la información pertinente para inversores, acreedores y demás proveedores de capital de riesgo.

- La emisión de estándares contables se debe realizar desde la perspectiva del inversor.

- Las revelaciones deben proporcionar a los inversionistas la información adicional requerida para comprender los elementos mencionados en los estados financieros, sus propiedades de medición y la exposición al riesgo.

- La información del valor razonable es la más relevante para la toma de decisiones financieras.

Este claro favorecimiento a la perspectiva del inversor en la conformación de las Normas Internacionales de Información Financiera se debe a que — según el con- 
sejo de la Financial Accounting Standard Board - los inversores, prestamistas y acreedores, existentes o potenciales, tienen la mayor necesidad crítica e inmediata de informarse adecuadamente de los estados financieros en pro del patrimonio común de la empresa, el mercado de capitales, el mercado de valores, los accionistas y los intereses de los diversos grupos (FASB, 2005; Pacter, 2011).

De este modo, con base en normas de alta calidad en materias contable y de revelación, la estandarización global haría transparentes y aportaría a la solución de diversos aspectos relativos al gobierno corporativo de las organizaciones: conflictos entre el consejo de administración y los accionistas mayoritarios y minoritarios; expectativas insatisfechas de reguladores bancarios, acreedores, prestamistas e inversionistas; conflictos societarios; distancia entre los procesos de gestión y administración, etc. Finalmente, se esperaría que con la estandarización se favoreciera el acceso de las corporaciones al mercado global y a una visión internacional y estandarizada del gobierno corporativo.

Sin embargo, como era de esperarse, asumir la normatividad internacional implica para los sistemas nacionales, como el austriaco UGB, una redefinición de sus códigos legales, sus normativas comerciales y de contabilidad, sus políticas y procedimientos de gobierno corporativo, y la revaluación de conceptos tradicionales como el de prudencia, que dentro de las normas internacionales es remplazado por el de valor razonable. El cuadro 1 resume algunas diferencias entre la manera como la norma austriaca UGB y las normas internacionales revelan la información. 


\section{Cuadro 1}

\section{Principales diferencias de revelación de información UGB, NIIF y NIC}

\begin{tabular}{|c|c|c|c|}
\hline & UGB & IFRS & NIC \\
\hline \multicolumn{4}{|c|}{ Presentación de los estados financieros } \\
\hline $\begin{array}{l}\text { Periodos } \\
\text { financieros } \\
\text { requeridos }\end{array}$ & $\begin{array}{l}\text { Los estados financieros y sus } \\
\text { notas deben presentarse en } \\
\text { forma comparativa, por lo } \\
\text { menos, con el periodo anterior } \\
(\S 201) \text {. El periodo dura } \\
\text { máximo } 12 \text { meses }(\$ 193)\end{array}$ & $\begin{array}{l}\text { Los estados financieros y } \\
\text { sus notas deben presentarse } \\
\text { en forma comparativa, por } \\
\text { lo menos, con el periodo } \\
\text { anterior }\end{array}$ & $\begin{array}{l}\text { Los estados financieros y sus } \\
\text { notas deben presentarse en } \\
\text { forma comparativa, por lo } \\
\text { menos, con el periodo anterior }\end{array}$ \\
\hline $\begin{array}{l}\text { Formato del } \\
\text { Balance General } \\
\text { y del Estado de } \\
\text { Resultados }\end{array}$ & $\begin{array}{l}\text { Los artículos } \$ 223 \mathrm{ff} \\
\text { establecen un formato } \\
\text { estándar. }\end{array}$ & $\begin{array}{l}\text { La IAS1 no establece un } \\
\text { formato estándar, pero sí } \\
\text { incluye una lista de partidas } \\
\text { mínimas menos prescriptivas } \\
\text { que los requisitos de la } \\
\text { regulación S-X }\end{array}$ & $\begin{array}{l}\text { No se establece un formato } \\
\text { estándar ni para el Balance } \\
\text { General ni para el Estado } \\
\text { de Variaciones en el Capital } \\
\text { Contable. } \\
\text { En la NIF A-5 se establecen } \\
\text { algunas reglas de presentación, } \\
\text { rubros que deben aparecer en el } \\
\text { Balance General y ejemplos. }\end{array}$ \\
\hline $\begin{array}{l}\text { Presentación } \\
\text { de deuda como } \\
\text { circulante } v s . \text { no } \\
\text { circulante en el } \\
\text { Balance General }\end{array}$ & $\begin{array}{l}\text { No regulación parecida en } \\
\text { UGB. Las deudas no se } \\
\text { distinguen entre circulante } \\
\text { o no circulante, sino } \\
\text { como deudas con fecha de } \\
\text { vencimiento o sin ella. }\end{array}$ & $\begin{array}{l}\text { Cuando se presenta una } \\
\text { violación a las restricciones } \\
\text { contractuales de una deuda } \\
\text { (covenant), la deuda debe } \\
\text { presentarse como circulante, } \\
\text { salvo cuando el acreedor } \\
\text { desista ejercer acción } \\
\text { (waiver) o apruebe modificar } \\
\text { el contrato antes del Balance } \\
\text { General. }\end{array}$ & $\begin{array}{l}\text { Cuando se presenta una } \\
\text { violación a las restricciones } \\
\text { contractuales de una deuda } \\
\text { (covenant), la deuda debe } \\
\text { presentarse como circulante, } \\
\text { salvo cuando el acreedor } \\
\text { desista ejercer acción (waiver) } \\
\text { o apruebe modificar el contrato } \\
\text { a más tardar un año después } \\
\text { del Balance General y la fecha } \\
\text { de cierre. }\end{array}$ \\
\hline $\begin{array}{l}\text { Presentación del } \\
\text { impuesto diferido } \\
\text { como circulante } \\
v s . \text { no circulante } \\
\text { en el Balance } \\
\text { General }\end{array}$ & No existe regulación parecida. & $\begin{array}{l}\text { Los impuestos se presentan } \\
\text { como no circulantes. }\end{array}$ & $\begin{array}{l}\text { Los impuestos se presentan } \\
\text { como no circulantes. }\end{array}$ \\
\hline $\begin{array}{l}\text { Estado de } \\
\text { Resultados: } \\
\text { clasificación de } \\
\text { gastos }\end{array}$ & $\begin{array}{l}\text { Se presenta los gastos e } \\
\text { ingresos según las formas } \\
\text { presentadas en } \$ 231 \text { : } \\
\text { considerando los cambios del } \\
\text { efectivo o considerando los } \\
\text { gastos de producción. }\end{array}$ & $\begin{array}{l}\text { Las empresas pueden } \\
\text { presentar sus costos y gastos } \\
\text { con base en su función o en } \\
\text { su naturaleza. Sin embargo, } \\
\text { si se presenta el formato } \\
\text { por función las notas deben } \\
\text { revelar cierta información } \\
\text { con respecto a la naturaleza } \\
\text { de los gastos. }\end{array}$ & $\begin{array}{l}\text { Se establecen dos tipos de } \\
\text { formatos que se pueden } \\
\text { combinar: por función y por } \\
\text { naturaleza. Si se elije por } \\
\text { función las notas deben revelar } \\
\text { la naturaleza de ciertas partidas } \\
\text { relevantes. }\end{array}$ \\
\hline $\begin{array}{l}\text { Estado de } \\
\text { resultados: partida } \\
\text { extraordianaria }\end{array}$ & $\begin{array}{l}\text { Según } \$ 233 \text { se constituye } \\
\text { ingresos extraordinarios. }\end{array}$ & No permitido. & No permitido. \\
\hline
\end{tabular}




\begin{tabular}{|c|c|c|c|}
\hline & UGB & TFRS & NIC \\
\hline \multicolumn{4}{|c|}{ Presentación de los estados financieros } \\
\hline $\begin{array}{l}\text { Estado de } \\
\text { resultados: } \\
\text { presentación } \\
\text { de operaciones } \\
\text { discontinuadas }\end{array}$ & No hay. & $\begin{array}{l}\text { Se utiliza esta clasificación } \\
\text { para entidades que estén a } \\
\text { la venta: una línea definida } \\
\text { de negocios importante, } \\
\text { un área geográfica, una } \\
\text { subsidiaria que fue adquirida } \\
\text { con la única intención de ser } \\
\text { vendida. }\end{array}$ & $\begin{array}{l}\text { Si las operaciones son } \\
\text { interrumpidas de manera } \\
\text { definitiva y representan, } \\
\text { además, una actividad } \\
\text { significativa para la entidad: } \\
\text { unidad generadora de efectivo, } \\
\text { por ejemplo. }\end{array}$ \\
\hline \multirow[t]{2}{*}{$\begin{array}{l}\text { Revelación de } \\
\text { medidas de } \\
\text { desempeño }\end{array}$} & $\begin{array}{l}\text { Según el UGB la empresa } \\
\text { debe publicar un informe de } \\
\text { gestión. La ley no regula las } \\
\text { medidas de desempeño que se } \\
\text { deban presentar. }\end{array}$ & $\begin{array}{l}\text { No se definen conceptos } \\
\text { como utilidad de operación; } \\
\text { por ello se presenta } \\
\text { diversidad en las prácticas de } \\
\text { presentación de subtotales en } \\
\text { el Estado de Resultados. }\end{array}$ & \\
\hline & UGB & IFRS & NIC \\
\hline \multicolumn{4}{|c|}{ Consolidación, contabilidad para negocios conjuntos (joint ventures) y método de participación } \\
\hline $\begin{array}{l}\text { Modelo de } \\
\text { consolidación }\end{array}$ & $\begin{array}{l}\text { Se basa en el concepto de poder } \\
\text { de control, que se define como } \\
\text { la capacidad de la compañía } \\
\text { tenedora para gobernar } \\
\text { las políticas financieras y } \\
\text { operativas con el fin de obtener } \\
\text { un beneficio (§244). }\end{array}$ & $\begin{array}{l}\text { Se basa en el concepto de } \\
\text { poder de control, que se } \\
\text { define como la capacidad } \\
\text { de la compañía tenedora } \\
\text { para gobernar las políticas } \\
\text { financieras y operativas con } \\
\text { el fin de obtener un beneficio. }\end{array}$ & $\begin{array}{l}\text { Se basa en el concepto de poder } \\
\text { de control, que se define como } \\
\text { la capacidad de la compañía } \\
\text { tenedora para gobernar } \\
\text { las políticas financieras y } \\
\text { operativas con el fin de obtener } \\
\text { un beneficio. }\end{array}$ \\
\hline $\begin{array}{l}\text { Entidades } \\
\text { establecidas } \\
\text { con propósitos } \\
\text { específicos (EPE) }\end{array}$ & $\begin{array}{l}\text { No regulación específica } \\
\text { sobre EPE. Son tratadas como } \\
\text { cualquier filial. }\end{array}$ & $\begin{array}{l}\text { Bajo la SIC 12, las EPE } \\
\text { (creadas para lograr un } \\
\text { objetivo determinado) } \\
\text { se consolidan cuando la } \\
\text { sustancia de la relación } \\
\text { indique que son controladas } \\
\text { por alguna entidad. }\end{array}$ & $\begin{array}{l}\text { La NIF B-8 requiere que } \\
\text { se consoliden las EPE si se } \\
\text { demuestra claramente que } \\
\text { las participación en ellas } \\
\text { constituye control. Con base } \\
\text { en la NIF C-7 es posible } \\
\text { argumentar que las entidades } \\
\text { ejercen influencia significativa } \\
\text { y no control. }\end{array}$ \\
\hline $\begin{array}{l}\text { Preparación } \\
\text { de estados } \\
\text { financieros } \\
\text { consolidados: en } \\
\text { general }\end{array}$ & $\begin{array}{l}\text { Se requiere, aunque existen } \\
\text { algunas excepciones. }\end{array}$ & $\begin{array}{l}\text { Se requiere, aunque existen } \\
\text { algunas excepciones para } \\
\text { ciertas industrias específicas } \\
\text { (por ejemplo, sociedades de } \\
\text { inversión). }\end{array}$ & $\begin{array}{l}\text { Se requiere; sin embargo, existe } \\
\text { una exención para compañías } \\
\text { informantes que son a su vez } \\
\text { controladas al } 100 \% \text { o en } \\
\text { menor porcentaje, siempre } \\
\text { y cuando cumplan ciertas } \\
\text { condiciones. }\end{array}$ \\
\hline $\begin{array}{l}\text { Presentación de } \\
\text { la participación } \\
\text { no controladora } \\
\text { (antes interés } \\
\text { minoritario) } \\
\end{array}$ & $\begin{array}{l}\text { Se presenta en el Balance } \\
\text { General como componente } \\
\text { por separado en el capital } \\
\text { contable. }\end{array}$ & $\begin{array}{l}\text { Se presenta en el Balance } \\
\text { General como componente } \\
\text { por separado en el capital } \\
\text { contable. }\end{array}$ & $\begin{array}{l}\text { Se presenta en el Balance } \\
\text { General, como componente por } \\
\text { separado en el capital contable. }\end{array}$ \\
\hline $\begin{array}{l}\text { Negocios } \\
\text { conjuntos }\end{array}$ & $\begin{array}{l}\text { Existe la posibilidad de } \\
\text { integrar este negocio } \\
\text { cumpliendo las reglas sobre } \\
\text { filiales asociadas (según } \\
\text { \$262) proporcionalmente. }\end{array}$ & $\begin{array}{l}\text { IAS 31, participaciones en } \\
\text { negocios conjuntos, permite } \\
\text { el método de consolidación } \\
\text { proporcional o el método de } \\
\text { participación. }\end{array}$ & $\begin{array}{l}\text { No se tiene una norma } \\
\text { particular, por lo que se aplica } \\
\text { la IAS } 31 \text { de manera supletoria. }\end{array}$ \\
\hline
\end{tabular}

Fuente: Elaboración propia a partir del escritorio de IFRS de Ernst \& Young (2009) 


\section{Antecedentes históricos}

Por tradición, la economía austriaca se relaciona estrechamente con la alemana. Esta interdependencia nace no sólo del idioma alemán compartido, sino también de variadas circunstancias culturales e históricas vividas en común por ambas naciones (Beller, 2009).

De forma general podría decirse que, por haber sido parte de Alemania, Austria continuó rigiéndose por muchas leyes alemanas, incluidas las comerciales relacionadas con la tradición del conservadurismo (Haller, 2002; Beller, 2009), aun después de que el final de la Segunda Guerra la consolidara como una nación independiente.

Décadas después, la economía austriaca aumentó marcadamente en importancia tras la caída del telón de acero en 1989, cuando los países del antiguo bloque comunista abrieron sus mercados a occidente; de igual forma, el gobierno conservador de los años 2000-2006, que quería forzar el débil mercado de capitales logró que la bolsa de valores de Viena fuera significativamente atractiva, en primer lugar, para la comunidad económica europea y, luego, para la comunidad internacional. A causa de esto, para atraer inversionistas, las empresas empezaron a considerar la importancia de informar al accionista sobre sus estados financieros; la perspectiva tradicional que consideraba al acreedor como centro de interés ya no fue suficiente. Por eso - y gracias a la afiliación con la Unión Europea (UE) que tenía desde que inició la década de los noventa el objetivo de la unificación y simplificación de las leyes y normas de sus naciones miembros-, Austria mejoró sus procesos de administración y divulgación de la información para accionistas internacionales, además de que buscó establecer y estandarizar normas internacionales y un código de gobierno corporativo, con el propósito de aumentar la comparabilidad y mejorar la calidad de la información para el inversor (Van Hulle, 1992).

A pesar de este empeño, ya en el siglo XXI, diversos eventos de orden nacional e internacional influyeron significativamente en las discusiones alrededor de la verdadera pertinencia de las normas internacionales de valoración: escándalos tales como los de las empresas Enron, Parmalat, Immofinanz y la crisis financiera y económica del año 2008 generaron interrogantes acerca de si las normas cumplen los objetivos para los cuales fueron creadas, si favorecen o no el fraude, o si con ellas se podría llegar a dar falsas imágenes del estado de las empresas (Véron, 2008; Egger, Samer y Bertl, 2008). 
Actualmente, las empresas austriacas, por pertenecer a la UE, están en proceso de asumir la estandarización total de sus procedimientos, ya sea por iniciativa propia, ya sea por disposición gremial; no obstante, ya es obligación nacional presentar algunas partidas dentro del marco de las normas internacionales. Por supuesto, a raíz de los escándalos y de la crisis, las normas y su conveniencia han sido constante tema de debate a causa de diversos aspectos que, para varios autores, las hace propiciatorias de fraudes (Véron, 2008); sobre todo se discute si la normatividad internacional debería ser convergida de manera total o sólo algunos de sus factores, o bien si la norma nacional debería conservar principios como el de prudencia que propendería por la regulación internacional y por el fortalecimiento del sector financiero, o bien si conceptos como el de prudencia deberían desaparecer, tal como lo asumen las NIIF para evitar malversaciones de la información financiera y contable (Van Hulle, 1992; Egger, Samer y Bertl, 2008; Mejía, 2011). El cuadro 2 presenta los principales temas de discusión que se presentan a partir de la convergencia de las normas nacionales alemanas, austriacas a las normas internacionales.

\section{Los principios de las NIIF}

El sistema de las NIIF parte de un método deductivo; la interpretación de las NIIF la realiza el International Financial Reporting Interpretations Committee (IFRIC), un comité que vela por encontrar una interpretación unitaria para cada caso de la misma manera que lo hace el sistema de las US-GAAP. Contrario al sistema nacional austriaco, en las NIIF los casos influyen directamente en las normas y sus interpretaciones. No obstante, contrario de los US-GAAP, en las NIIF las jerarquías de los principios de la UGB se conservan. Los principios básicos de las NIIF, según lo estipulado en su propio marco teórico, son los siguientes (IFRS, 2010):

- Acotación. Se consideran las ganancias y los gastos independientemente de la fecha del pago.

- Empresa en marcha. Durante el proceso de valorización de los bienes se debe presuponer que la empresa existirá en el futuro. Sólo razones de dudas fundadas permitirían obviar este principio.

- Entendimiento. Se debe presentar la información de modo que personas con conocimiento en economía y finanzas puedan entenderla fácilmente. La complejidad no es razón para excluir a nadie de la posibilidad de acceder a la información en la medida que ésta es necesaria dentro del proceso de tomar decisiones. 


\section{Cuadro 2 \\ Puntos de discusión surgidos de la convergencia de las normas nacionales alemana (austriaca) a las normas internacionales NIIF}

\begin{tabular}{|c|c|c|}
\hline Punto de discusión & NIIF & $\begin{array}{c}\text { Principios de contabilidad alemanes, } \\
\text { austriacos }\end{array}$ \\
\hline $\begin{array}{l}\text { Combinaciones } \\
\text { comerciales }\end{array}$ & $\begin{array}{l}\text { NIIF 3: Se debe usar el método de } \\
\text { compras; la mancomunación de } \\
\text { intereses está prohibida. }\end{array}$ & $\begin{array}{l}\text { Ciertas combinaciones de negocios se } \\
\text { pueden contabilizar como comunicaciones } \\
\text { de intereses aun cuando se pueda identificar } \\
\text { un adquiriente }\end{array}$ \\
\hline $\begin{array}{l}\text { Crédito mercantil en la } \\
\text { consolidación }\end{array}$ & $\begin{array}{l}\text { NIIF 3: No se amortiza, pero se } \\
\text { examina anualmente para detectar } \\
\text { posibles deterioros (en vigor desde el } \\
31 \text { de marzo de 2004). }\end{array}$ & $\begin{array}{l}\text { El crédito mercantil que surge en } \\
\text { la consolidación se puede deducir } \\
\text { inmediatamente contra el capital contable }\end{array}$ \\
\hline $\begin{array}{l}\text { Activos intangibles } \\
\text { internamente } \\
\text { generados }\end{array}$ & $\begin{array}{l}\text { NIC 38: El crédito mercantil } \\
\text { internamente generado se puede } \\
\text { reconocer como un activo bajo ciertas } \\
\text { condiciones. }\end{array}$ & $\begin{array}{l}\text { No se deben reconocer los activos } \\
\text { intangibles internamente generados que se } \\
\text { esperan proporcionen un servicio continuo } \\
\text { para la empresa }\end{array}$ \\
\hline $\begin{array}{l}\text { Conversión de moneda } \\
\text { extranjera }\end{array}$ & $\begin{array}{l}\text { NIC 21: Las partidas monetarias en } \\
\text { moneda extranjera se deben reportar } \\
\text { usando la tasa de cierre. }\end{array}$ & $\begin{array}{l}\text { Los saldos monetarios en moneda extranjera } \\
\text { generalmente se convierten a la peor tasa de } \\
\text { las transacciones y a las tasas de cierre con } \\
\text { la finalidad de evitar el reconocimiento de } \\
\text { ganancias sobre saldos no liquidados. }\end{array}$ \\
\hline Arrendamientos & $\begin{array}{l}\text { NIC 17: Distingue entre los } \\
\text { arrendamientos financieros y } \\
\text { los arrendamientos operativos y } \\
\text { proporciona lineamientos para } \\
\text { clasificarlos. }\end{array}$ & $\begin{array}{l}\text { Por lo general, los arrendamientos se } \\
\text { clasifican de acuerdo con las reglas fiscales; } \\
\text { por consiguiente, los arrendamientos se } \\
\text { reconocen rara vez como arrendamientos } \\
\text { financieros. }\end{array}$ \\
\hline $\begin{array}{l}\text { Valuación de } \\
\text { inventarios }\end{array}$ & $\begin{array}{l}\text { NIC 2: Requiere que los inventarios } \\
\text { se expresen al valor más bajo entre } \\
\text { el precio de costo y el valor neto de } \\
\text { realización. }\end{array}$ & $\begin{array}{l}\text { Los inventarios se pueden expresar al valor } \\
\text { más bajo entre el precio de costo, el valor } \\
\text { neto de realización o el costo de remplazo. }\end{array}$ \\
\hline $\begin{array}{l}\text { Contratos de } \\
\text { construcción }\end{array}$ & $\begin{array}{l}\text { NIC 11: Se debe usar la etapa de } \\
\text { terminación de la actividad del } \\
\text { contrato a la fecha del Balance } \\
\text { General para reconocer los ingresos } \\
\text { del contrato. }\end{array}$ & $\begin{array}{l}\text { En general, se usa el método de contrato } \\
\text { completado por el reconocimiento de los } \\
\text { ingresos sobre los contratos y servicios de } \\
\text { construcción. }\end{array}$ \\
\hline $\begin{array}{l}\text { Exclusión de } \\
\text { subsidiarias de la } \\
\text { consolidación }\end{array}$ & $\begin{array}{l}\text { NIC 27: Las subsidiarias cuyas } \\
\text { actividades son disímiles a las de su } \\
\text { compañía matriz se debe consolidar }\end{array}$ & $\begin{array}{l}\text { Ciertas subsidiarias con las actividades } \\
\text { disímiles se deben excluir de la } \\
\text { consolidación. }\end{array}$ \\
\hline Costos de inicio & $\begin{array}{l}\text { NIC 38: Los costos de inicio se deben } \\
\text { cargar a gastos cuando se incurre en } \\
\text { ellos. }\end{array}$ & $\begin{array}{l}\text { Los costos de inicio se pueden capitalizar y } \\
\text { amortizar a lo largo de cuatro años. }\end{array}$ \\
\hline
\end{tabular}

Fuente: Doupnik y Perea (2007) 
- Relevancia. Según el principio de relevancia, la información debe ser importante para el proceso de toma de decisión. Se evalúa la información predictiva, existente en el pasado o en el presente, según el mismo principio. La información pasada puede ser importante si influyó en decisiones pasadas que podrán tomarse en cuenta para decisiones en el presente. El principio de materialidad es parte del principio de relevancia y expresa la necesidad de considerar que información es relativamente importante para tomar decisiones económicas.

- Confiabilidad. La información se considera confiable si no tiene errores y no es cohibida. Esto porque cierta información puede ser importante, pero su presentación podría ser engañosa; por eso, es trascendental, para generar confiabilidad, tener en cuenta otros principios como el de punto de vista económico que consiste en evaluar eventos por sus efectos económicos y no por sus efectos legales, por ejemplo, al vender un sector de la propia compañía se tiene derecho a recibir ganancias; el de representación concienzuda: la información debe representar todas las transacciones y otros eventos concienzudamente aun cuando sea difícil evaluar eventos futuros y sus efectos financieros; el de prevalencia: la esencia sobre la forma (substance over form); el de neutralidad: la información no debe presentar distorsiones; de totalidad: el balance tiene que contener toda la información necesaria, limitada por costos e importancia; y el de prudencia: se debe considerar la inseguridad de la evaluación apropiadamente y el cuidado en la valoración de partidas. El principio de prudencia no permite la creación de reservas escondidas o provisiones excesivas.

- Comparabilidad. Los usuarios del balance anual tienen que poder comparar los balances de varios años y varias empresas. La medida dentro de una cooperación debe ser consistente para todas las empresas y durante varios años. Por eso, se debe informar sobre los métodos y políticas de contabilidad de los que se hizo uso y preferentemente no cambiarlos o informar las razones del cambio si éste llega a hacerse.

- Valor justo o razonable. Considerando todos los principios anteriores, las posiciones del balance deben representar un valor justo, real y verdadero que considere tanto riesgos como ganancias potenciales.

\section{Generalidades sobre las normas nacionales austriacas}

Teniendo como objetivo el balance, las leyes austriacas reconocen tres tipos de contabilidades, ya sea para determinar los impuestos, ya sea para organizar las 
empresas, ya sea para alimentar los datos que ofrecen las NIIF (Hayn, Sven, Waldersee y Graf, 2010; IFRS 2010; RIS,2010):

\section{a) La contabilidad enfocada en los impuestos}

La contabilidad enfocada en los impuestos en Austria se divide en dos leyes, a saber: Einkommenssteuergesetz (leyes de retención salarial por impuestos) y Koerperschaftssteuergesetz (leyes de impuestos para entidades). Enseguida se describirá brevemente cada una:

\section{Einkommenssteuergesetz (EStG)}

Bajo este régimen se consideran sujetos tributarios solamente a entes de existencia humana, dado que el impuesto se retiene de los ingresos por persona. Quienes tienen domicilio en Austria deben tributar con base en todos sus ingresos; quienes no sólo tienen que pagar los ingresos que se originen en Austria. Los principios del EStG son (RIS, 2010):

- Imposición individual: cada persona tiene que tributar individualmente.

- Principio neto: se grava el beneficio, y no las ventas, con impuestos.

- Principio de la progresión: los impuestos aumentan en un grado mayor, según los ingresos, de manera no proporcional.

- Principio del trato sintético: todos los ingresos son medidos bajo el mismo estándar.

- Principio de gravamen por etapas: cada etapa tiene una duración de máximo un año.

El estado austriaco considera como ingresos factibles de gravamen los siguientes:

- Ingresos provenientes de la agricultura y la silvicultura.

- Ingresos provenientes del trabajo por cuenta propia.

- Ingresos por ganancias empresariales.

- Ingresos de los de empleados.

- Ingresos por capital.

- Ingresos por finca raíz (alquiler y arrendamiento).

Ingresos menos gastos es la base para calcular los impuestos. Según el artículo 5 del EStG es obligatorio que se realice una comparación del patrimonio si las ventas 
exceden 700000 euros; si las ventas no exceden este límite se pueden calcular los ingresos menos los gastos. (RIS, 2010; Hayn, Sven, Waldersee y Graf, 2010)

\section{Koerperschaftssteuergesetz (KStG)}

Desde este régimen se consideran como sujetos tributarios únicamente a entes de existencia jurídica, es decir, sociedades con sede o dirección en Austria que tienen el deber de tributar con base en todos sus ingresos; las empresas que no residen en Austria sólo pagan los ingresos que se originen allí. Los principios del KStG son los siguientes (RIS, 2010):

- Impuesto para corporaciones

- Tasa de impuesto unitaria

b) Unternehmensgesetzbuch (UGB) contabilidad para empresas (antes: Handelsgesetzbuch HGB: contabilidad para negocios)

La ley empresarial (RIS, 2010) define como empresarios a las personas o entidades que dirigen una empresa; una empresa es una organización de actividad autónoma y económica que funciona no necesariamente con el objetivo de obtener beneficios (Loitlsberger, 2000). En Austria, se consideran empresarios, desde la perspectiva jurídica, a las siguientes organizaciones: aktiengesellschaften (sociedades anónimas), gesellschaften mit beschraenkter haftung (sociedades con responsabilidad limitada), sociedades europeas y otras. Según el artículo 222 del UGB (RIS, 2010), los representantes de las empresas capitalistas, cuyos socios aportan únicamente capital, tienen que presentar un balance anual, que incluye un informe sobre su situación financiera, en un plazo no mayor a cinco meses después de la fecha de cierre. Dicho balance tiene que representar una imagen real de la empresa, de sus activos, de su situación financiera y de su situación de rentabilidad (Zwirner, 2007).

c) Relación de las empresas austriacas con las Normas Internacionales de Información Financiera

Según el reglamento 1606/2002 de la Unión Europea del año 2002 (EUR-LEX, 2010), las empresas europeas que están inscritas en las bolsas de valores europeas (se incluyen bancos y empresas de seguros) tienen que presentar un balance anual consolidado de acuerdo con los lineamientos de las NIIF. Los miembros de la UE 
también pueden exigir la aplicación de las NIIF para las empresas filiales de empresas cotizadas o, generalmente, para todas las empresas. Austria no eligió estas opciones del reglamento (EUR-LEX, 2010; Ehrlich, 2011; Hayn, Sven, Waldersee y Graf, 2010).

No obstante, el artículo 245 del UGB permite a las empresas maternas abstenerse de la presentación consolidada si presentan un balance consolidado según el artículo 4 del reglamento 1606/2002 de la UE (EUR-LEX, 2010); de todos modos, es obligatorio para las organizaciones referir los reglamentos utilizados (RIS, 2010; EUR-LEX, 2010).

\section{Los principios de la UGB}

La UGB está basada en nueve principios mayores que son deducidos de los principios básicos de la contabilidad, los cuales están definidos parcialmente por la ley, pues parten principalmente del uso comercial y contable. Dichos principios son los siguientes (Egger et al., 2008; Wünsche, 2011):

1. Verdad. El balance tiene que representar la situación de la empresa de una manera verdadera y sin arbitrariedades.

2. Totalidad. El balance tiene que contener todos los activos y pasivos, el estado de pérdidas y ganancias y todas las ganancias y gastos. En el UGB se conocen algunas excepciones, por ejemplo, el libre derecho de tomar en cuenta o no factores tales como el valor social a la hora de adquirir una empresa.

3. Claridad. El balance tiene que tener una estructura clara, ser coherente.

4. Empresa en marcha. Durante el proceso de valorización de los bienes se debe presuponer que la empresa existirá en el futuro. Sólo razones de dudas fundadas permitirían obviar este principio.

5. Valoración individual. Sólo bienes de valor pequeño, de entrada periódica y pérdida física periódica se puede valorar con el método del precio promedio.

6. Anualidad. La valoración de bienes y deudas tiene que tener efecto a la fecha de vencimiento del balance anual.

7. Demarcación de periodos. Se consideran las ganancias y los gastos independientemente de la fecha del pago.

8. Uniformidad. La estructura y los métodos del balance no deben cambiar entre periodos. 
9. Prudencia. Sólo se consideran ganancias aquellas que se han logrado hasta el día de vencimiento (principio de la realización); en caso contrario, se consideran los riesgos y pérdidas que sean previsibles (principio de la disparidad). Si hay más de un valor para los bienes del balance, se elegirá el más bajo (principio del valor bajo). Si hay más de un valor para las deudas del balance, se elegirá el más alto (principio del valor alto).

Puesto que la ley austriaca está basada en principios, los casos aislados no están reglados; en contraposición a las US-GAAP (General Agreed Accounting Principles of the United States of America), el UGB es un código de leyes mediante el cual los estamentos pertinentes deciden que interpretación dar a cada caso, ya que los juicios anteriores no tienen eficacia legal.

\section{El conservadurismo o principio de prudencia}

El concepto de conservadurismo ha evolucionado a través de los años en la medida que los contadores han preferido que las estimaciones o errores de apreciación resultaran subvalorados y no sobrevalorados. El conservadurismo propende a ello porque, en la práctica, los inventarios sean valorados al más bajo costo del mercado; su problema es el carácter pesimista porque puede generar pérdidas virtuales de activos y excesivas reservas de pasivos. (Bailley y Miller, 1999).

El conservadurismo se encuentra en la denominación del principio prudencia del UGB (RIS, 2010); asimismo, se relaciona directamente con el principio de realización, valor bajo, imparidad y valor alto. En este orden de ideas, el principio de la prudencia nace de la necesidad de proteger al acreedor y de evitar un valor de la empresa demasiado grande; de esta manera, se propician reservas escondidas y reservas pasivas altas en las organizaciones, lo que ocasiona que no se refleje el valor justo de las empresas, sino su mínimo valor. La utilización del valor histórico como límite máximo lleva a una imagen distorsionada de la realidad empresarial porque no se está representando el valor real de los bienes; en resumidas cuentas, esto se debe a que el conservadurismo debe servir a la conservación del capital y a la protección de una falta súbita de liquidez.

\section{La crisis del concepto prudencia dentro del marco conceptual de las NIIF}

Las divergencias entre los conceptos propios del sistema nacional, UGB, en contraposición con el global, NIIF, tienen su base en "las características cualitativas 
necesarias para que la información contable y financiera sea considerada útil para la toma de decisiones económicas" (Mejía, 2011). Mientras que las UGB consideran fundamentales los principios de veracidad, totalidad, claridad y prudencia para dar a conocer el estado financiero de una empresa, las NIIF consideran que estos estados se pueden interpretar a partir de los principios relevancia y representación fiel con base en la confiabilidad y cuatro características, no condicionantes entre sí, que mejoran la calidad de la información: comparabilidad, verificabilidad, oportunidad y comprensibilidad (Van Hulle, 1992; Mejía, 2011).

El concepto prudencia no es mencionado en el marco conceptual de las NIIF, mientras que otros como esencia sobre forma están implícitos en la representación fiel y en la definición de los elementos de los estados financieros (IFRS, 2010; Pacter, 2011); esto porque, según las NIIF, al reconocer la existencia de los elementos (activos, pasivos, ingresos, patrimonio, rendimientos, ingresos y gastos) debe prestarse atención a la realidad económica que subyace tras estos elementos (sustancia) y no meramente a los formatos legales (forma). Contrario a esto, la prudencia podría permitir a quienes presenten la información mostrar reducidas las utilidades y el patrimonio, por ejemplo, trasladándolos de un periodo a otro, reconociendo los gastos anticipadamente para así no reconocerlos en el futuro, creando provisiones excesivas para la protección de activos, basándose en indicios para calcular deterioros, calculando contingencias como pasivos, convirtiendo ingresos en recuperaciones en un periodo posterior, etcétera.

Por supuesto, los defensores de la prudencia aducen que aunque estas prácticas afectarían a inversores y pequeños accionistas, dentro del sector financiero, el conservadurismo - entendido como la precaución a la hora de establecer juicios en estado de incertidumbre de modo que los activos e ingresos no se expresen en exceso y las obligaciones y gastos no se expresen en defecto- que conlleva la prudencia ha protegido la economía global de las crisis financieras (FASB, 2010; Mejía, 2011).

Por último, tanto el consejo de la Financial Accounting Standard Board (FASB, 2010) como el General Agreed Accounting Principles of the United States of America (US- GAAP) (Van Hulle, 1992) prefirieron no incluir el conservadurismo (la prudencia) dentro del marco conceptual de las normas internacionales porque éste no resultaba útil a los inversores, ya que podía ser manipulado para dar una información ficticia acerca de los estados financieros de las empresas y entrar en conflicto con principios como la fidelidad de representación, la comparabilidad, la 
coherencia y la neutralidad; lo anterior ocasiona que los preparadores de la información la filtren, quitando así el derecho a los usuarios de decidir qué información es relevante o no (Palavecinos y Álvarez, 2006).

\section{El principio del valor justo como alternativa al de la prudencia}

El principio denominado valor justo (o valor razonable) en las NIIF pretende incentivar en las organizaciones un sistema de información de los procesos más transparente para los inversionistas, la cual ofrezca una imagen realista del valor de las empresas. Subordina, por tanto, el significado del principio de la prudencia. El objetivo es la presentación de una imagen menos distorsionada, incluso optimista, de la empresa que mira por encima del riesgo de un valor demasiado grande.

Para entender esto se debe recordar que existen tres métodos básicos para establecer el precio de un bien de acuerdo a su valoración: 1) El histórico, valor durante el momento de la compra denominado; 2) el valor presente neto (VPN) que representa el valor presente del bien tomando en cuenta, en prospectiva, las posibles futuras ganancias de la empresa; 3) el precio de mercado, que es el valor que el respectivo mercado pagaría en la actualidad por el bien (Lopes, 2010; Palavecinos y Álvarez, 2006).

En este sentido, el valor justo de bienes es principalmente el valor del mercado o el costo de reposición. Si no hay un valor del mercado adecuado, se utiliza el valor presente neto (VPN) y si ése no es seguro se usan los costos históricos por dos razones: 1) el principio lleva al riesgo de la subjetividad, esto es, el precio del mercado a veces está influido por especulaciones y no podría representar un valor real o sostenible; 2) el VPN se basa en ganancias futuras que, en esencia, sólo son estimaciones de la empresa.

Esto se debe a que las NIIF ofrecen un rango bastante amplio de elección que se condiciona apenas, precisamente, al deber de la organización de explicar el método de valoración que se utilizó; es decir, a la justificación de su elección, por lo que este rango podría reducir la comparabilidad entre los balances. En definitiva, el uso de valores presentes no refleja el principio de la utilidad del bien.

Esto evitaría las distintas doctrinas concernientes al concepto prudencia que llevan a diferencias graves en el uso de las normas tales como las distintas apreciaciones del valor social, la amortización, las reservas o la reevaluación que han asumido 
las empresas. Por ejemplo, la UGB considera que no se debería tomar un valor social, puesto que éste no es adquirido por la empresa; por el contrario, las NIIF prevén este tipo de valores y solicitan incluirlos en el balance. Para el caso de la amortización, por ejemplo, el UGB sostiene que la empresa debería atenerse a la amortización fiscal; las NIIF, en cambio, consideran una amortización calculada de acuerdo con la utilización del bien. Otro ejemplo más, a diferencia de las UGB, las NIIF prohíben reservas para provisión para gastos. Como último ejemplo, una reevaluación de bienes, algo que es prohibido por el UGB, se puede realizar sin ningún problema en balances que observen las disposiciones de las NIIF (Loitlsberger, 2000; Hayn, 2004).

No obstante lo anterior, se debe tener claro que el uso de las NIIF lleva al reconocimiento de un patrimonio más grande y el tamaño del patrimonio influye en las posibilidades de crédito de una empresa; si el valor no representa la realidad financiera de una empresa, se corre el riesgo de una evaluación falsa del potencial financiero de la misma. Así, demostrar de manera sistemática un patrimonio demasiado grande aumenta el riesgo de acelerar mecanismos de corrección por parte del mercado; si estos mecanismos afectan muchas empresas se genera una crisis económica (Zwirner, 2007).

Es por eso que después de la crisis financiera y económica del año 2008, la crítica a las NIIF se incrementó. En el centro de la crítica está la cuestión sobre si el principio del valor justo no es una agresión grave a los principios mismos de las NIIF en la medida en que la dependencia del valor justo al funcionamiento de los mercados viola el principio de la confiabilidad; el rango de libertad afecta directamente los principios de comparabilidad y de confiabilidad (Palavecinos, 2006; Zwirner, 2007) debido a que están directamente relacionados con la calidad de la información suministrada. Los rangos de libertad aumentan la posibilidad de fraude y dificultan la labor de los auditores y de los sistemas de control.

Sin embargo, pese a las críticas, las instituciones globales, europeas y austriacas favorecen la dilatación del uso de las NIIF con el argumento de la unificación, comparabilidad y simplificación; incluso se está gestando actualmente el proyecto de establecer las NIIF en las pequeñas y medianas empresas (Pyme) de una forma simplificada, primero en Europa y luego en América (Fortin, Hirata y Cutler, 2010).

El cuadro 3 muestra como se han manipulado la revelación de las utilidades con métodos contables que distorsionan los principios de las NIIF. 


\section{Cuadro 3}

\section{Información distorsionada de los principios de las NIIF}

\begin{tabular}{l|l|l}
\hline Estados financieros & $\begin{array}{l}\text { Alteración de las } \\
\text { intenciones de las NIIF }\end{array}$ & Tratamiento “conservador" \\
\hline Ingresos ordinarios & Causaciones agresivas & Venta a plazos o recuperación de costos \\
\hline Inventarios & Tratamientos PEPS (IFRS) & $\begin{array}{l}\text { UEPS (donde se permita; IFRS no lo } \\
\text { permite ya) }\end{array}$ \\
\hline Depreciación & $\begin{array}{l}\text { Línea recta (usual con los IFRS) } \\
\text { con alto valor de salvamento }\end{array}$ & $\begin{array}{l}\text { Métodos de patrón de desgaste acelerado } \\
\text { (menor valor de salvamento) }\end{array}$ \\
\hline Garantías o deudas malas & Estimados altos & Estimados bajos \\
\hline Periodo de amortización & Mayor o creciente & Menor o decreciente \\
\hline Gastos discrecionales & Diferidos & Contraídos \\
\hline Contingencias & Sólo en notas de pie de página & Causación \\
\hline Compensación gerencial & Con base en ganancias contables & Con base en ganancias económicas \\
\hline $\begin{array}{l}\text { Ajustes del ejercicio } \\
\text { anterior }\end{array}$ & Frecuentes & Poco frecuentes \\
\hline Cambio de auditores & Frecuente & Poco frecuente \\
\hline Costos & Capitalización & Se reconocen como gastos \\
\hline
\end{tabular}

Fuente: Greuning (2010)

\section{Conclusiones}

Dentro del proceso de convergencia que se ha dado en Austria, esto es, de las normas nacionales austriacas UGB a las internacionales NIIF, el concepto prudencia, ligado al principio del conservadurismo, ha entrado en crisis debido a que éste ha sido eliminado de las últimas a cambio del concepto valor justo o valor razonable que, en resumidas cuentas, prefiere favorecer la perspectiva del inversor a la del acreedor. La prudencia ha sido criticada y, efectivamente, eliminada de las normas internacionales porque podría permitir, entre otras cosas, en la revelación de los estados financieros el reconocimiento anticipado de gastos (y pasivos) o la reducción deliberada de ingresos (y de activo) a fin de presentar como mejores los resultados de periodos futuros. Por supuesto, desde la perspectiva del inversor, esta información parece engañosa y poco útil, pues no ayuda a la toma de decisiones económicas.

No obstante, los propósitos unificadores, globalizadores, en pro de la comparabilidad, simplificación y utilidad de la información para los inversores que pretenden las Normas Internacionales de Información Financiera, existen para diversos autores dudas profundas acerca de si las NIIF, tal y como se conciben actualmente, son adecuadas para mostrar el valor real de una empresa. Según ellos, la interpretación 
que actualmente se le da al principio del valor justo atenta contra los principios de confianza y comparabilidad. Los casos recientes de valores injustos ofrecidos por diversas empresas en los años 2008 y 2009 mostraron la tenuidad del sistema de las NIIF. Incluso los defensores del valor justo ven la necesidad de mejorar la protección de los acreedores. Los gobiernos de los estados que utilizan las NIIF y el IASB están trabajando en dar soluciones para mejorar la valuación de bienes financieros cuyos valores mercantiles han sido muy volátiles en los últimos años. El primer efecto es la adopción del IFRS 7 (Véron, 2008) que pretende interpretar de manera más aterrizada las normas.

En conclusión, aunque la paulatina conversión de las normativas nacionales a las normas internacionales es un hecho, la desaparición del concepto prudencia también lo será, por lo menos en Austria, en la medida que no sea recategorizado - como característica cualitativa, por ejemplo- dentro de las normas nacionales. De todas maneras, es necesario continuar la reflexión acerca de si el principio valor justo o razonable cumple a cabalidad con las expectativas de revelación e interpretación internacionales y locales, y si realmente favorece la toma de decisiones y un adecuado gobierno corporativo de las empresas globales.

\section{Recomendaciones}

En el momento las leyes austriacas sólo prevén las NIIF para balances consolidados; esto implica que todavía se deban presentar los balances individuales según el UGB para así asegurar la protección del acreedor. No obstante, la Unión Europea insiste en unificar las leyes y, a través de las NIIF, ofrecer un estándar internacional que dé la posibilidad de la comparabilidad internacional. Según la comunidad europea, se puede lograr de este modo una reducción de leyes y una simplificación de procedimientos para las empresas. En este sentido, las NIIF para Pyme serían, según ellos, de gran valor para los pequeños y medianos empresarios pues les permitiría moverse más ágilmente dentro de los mercados internacionales.

Austria, como miembro de la Unión Europea, es un país de bastante fuerza económica, pero de tamaño pequeño que ya ha aplicado las NIIF; por supuesto, esta decisión le obliga a tomar parte en la discusión sobre las reformas que deberían aplicársele a las NIIF. Creemos que otros países, incluso latinoamericanos, deberían tomar parte de la discusión respecto a principios tales como los de prudencia y valor justo, puesto que éstos tienen que ver, por un lado, con el desarrollo, internacionalización y comparabilidad de las economías y, por otro, con la corrupción 
el fraude y las crisis económicas. Aprender de la experiencia de otras naciones que han acogido la norma ayudaría a forzar o no su aplicación de acuerdo con los intereses económicos y sociales nacionales.

\section{Referencias}

Bailley, L. y P. Miller (1999). Guía de Auditoría. Una rexpresión comprehensiva de las Normas de Auditoría (SAS), de Testimonio (SSAE), de Servicios de Contabilidad y Revisión (SQCS) y de Control de Calidad (SQCS). 1988-99. Madrid: Harcourt Brace de España.

Beller, S. (2009). Historia de Austria. Madrid: Akal.

Coenenberg, A., A. Haller y K. Marten (1999). Accounting education for professionals in Germany current state and new challenges. Journal of Accounting Education 17(4): 367-390.

Doupnik, T. y H. Perea (2007). Contabilidad internacional. México: Mc.Graw Hill.

Egger, A., H. Samer y R. Bertl (2008). Der Jahresabschluss nach dem Unternehmensgesetzbuch, Band 1 Der Einzelabschluss (12. Auflage), Linde, Wien, XXIX, 750 Seiten.

Ehrlich, S. (2011). Die Bilanzierung und Bewertung von Schulden auf Basis der internationalen Standards nach IAS/IFRS. im Vergleich zum deutschen Handelsrecht. Münich. E Verlag.

Escritorio de IFRS de Ernst \& Young (2009). Principales diferencias USGAAPIFRS-NIF. México:Mancera

EUR-LEX (2010). El acceso al Derecho de la Unión Europea. Disponible en http:// eur-lex.europa.eu/.

Financial Accounting Standard Boards (2005). Board Meet Handout. Conceptual Framework. Disponible en http://www.fasb.org/news/05-25-05.pdf/. 
Fortin, H., A. Hirata y K. Cutler, (2010) Contabilidad y crecimiento en América Latina y el Caribe. Mejorando la información financiera de las empresas para fomentar el Desarrollo económico de la región. Washington: Banco Mundial.

Greuning, H. (2010). Estándares internacionales de Información Financiera: Guía práctica. Bogotá: Banco Mundial.

Haller, A. (2002). Financial accounting developments in the European Union: past events and future prospects. European Accounting Review 11(1): 153-190.

Hayn, S. y G. Waldersee, (2010). IFRS/US-GAAP/HGB im Vergleich. Synoptische Darstellung für den Einzel-und Konzernabschluss. 6. Auflage.

Institute of Certified Public Accountants, AICPA (2009). IFRS. Trends \& Techniques. Washington.

International Accounting Standards Committee Fundation (2010). Online Access to the unaccompanied IFRSs. Disponible en http://www.ifrs.org/IFRSs/IFRS. htm.

Loitlsberger, E. (2000). Grundkonzepte der Betriebswirtschaftslehre. Oldenbourg: Verlag.

Lopes de Sa, A. (2010). Ética e instrumentalismo normativo contable. Revista internacional Legis de Contabilidad y Auditoría:111-148.

Mejía, J. (2011). La crisis de la prudencia en la convergencia contable internacional. Revista Internacional Legis de Contabilidad y Auditoría: 135-182.

Pacter, P. (2011). Developing Accounting Standards Consistent with the CFA Institute's vision. Disponible en http://ifrs.org/Investor+resources/ 2011+perspectives/June+2011+perspectives/CFA+Institute.html

Palavecinos, B. y D. Álvarez (2006). Alcances sobre el concepto de valor razonable. In: CAPIV Review, 4 
Rechtsinformationssystem des Bundeskanzleramtes der Republik Oesterreich (2010). Disponible en http://www.ris.bka.gv.at/.

Van Hulle, K. (1992). Harmonization of accounting standards A view from the European community. European Accounting Review 1(1): 161-172.

Véron, N. (2008). Fair Value Accounting Is the Wrong Scapegoat for This Crisis. Revue d'Economie Financière and Risques, forthcoming June.

Wünsche, M. (2011). Unterrichtsskript Bilanzbuchhaltung: Mit BilMoG-Änderungen, Steuerrecht und IFRS (Vol. 4). GRIN Verlag GmbH.

Zwirner, C. (2007). IFRS-Bilanzierungspraxis - Umsetzungs- und Bewertungsunterschiede in der Rechnungslegung. Erich Schmidt Verlag. 